\title{
Application of fuzzy logic in lift energy efficiency classification
}

\author{
Tomasz Krakowski $(\mathbb{D} \cdot$ Hubert Ruta
}

Received: 19 January 2018 / Accepted: 30 April 2019 / Published online: 5 June 2019

(C) The Author(s) 2019

\begin{abstract}
The study outlines a new approach to lift energy efficiency classification based on a heuristic estimator using the energy performance parameters of a lift installation registered over its weekly duty cycle. Due to the fact that evaluations of the energy performance by commonly applied methods involve a number of variables and complex nonlinear dependencies, the expert model is developed using the fuzzy logic approach. The underlying objectives are defined alongside the energy performance and operating parameters of a lift installation during the ride and in the standby mode. The estimator is based on the operational equipment effectiveness for each mode of lift operation and membership functions (model input and output) are defined. The method was verified by measurements taken on a real object. This study summarises the measurement results and lift energy classification data obtained by the new method, the final results are presented in figures illustrating the energy efficiency variations in the running mode and as the average energy efficiency ratings on each day and over the whole week.
\end{abstract}

Keywords Elevators · Energy efficiency classification · Fuzzy logic

T. Krakowski $(\bowtie) \cdot$ H. Ruta

AGH University of Science and Technology, Kraków, Poland e-mail: krakowsk@agh.edu.pl

\section{Introduction}

Issues related to use of lifting devices are not widely discussed within world's literature. Main scientific trends deliberated by authors concern broadly understood mathematical analysis connected with vibrations of rope systems, acoustic emission generated during the operation (Lonkwic and Szydło 2016), and in research papers (Syta and Lonkwic 2016; Longwic and Szydło 2017; Szydło et al. 2016), authors describe results of their own investigations of braking systems of the lifts. Elevators are basic equipment of the building and increasing their energy efficiency is crucial in terms of the whole building efficiency (Goldstein and Eley 2014; Zhou et al. 2012). Energy that they use depends on the device type, location of installation and usage intensity connected to passenger traffic. Construction factors (device type, drive and control type, roping ratio and overbalancing of the system, etc.) and operation parameters (e.g. rated speed, acceleration and deceleration, travel distance, direction of travel, nominal load, number of trips) are what influences the energy efficiency. Impact of some of these factors on energy consumption has been described by authors (Anand and Mahesh 2017; Papanikolaou et al. 2017; Tukia et al. 2016a, b; Siikonen et al. 2010; Nipkow and Schalcher 2005). Use of new technical solutions can significantly contribute in decreasing the energy used by lifts and improve their energy efficiency. One of the basic elements impacting the improvement of energy efficiency of the lift is drive and control type. In publications (Anand and Mahesh 2016; Goergiev and Mirchevski 2012; Karlis 2014), 
authors point out the benefits of using the newest solutions. Issues related to energy efficiency of lifting devices were also raised by authors (Al-Sharif 2004; Almeida et al. 2012; Barney 2013; Doolaard 1992; Lorente et al. 2010; Nipkow and Schalcher 2005; Schroeder 1980, 1988, Tukia et al. 2016a, b).

Evaluations of the energy performance by commonly applied methods (VDI 4707-1 2009; ISO 25745-2 2015; E4 Project 2010) may prove inadequate and in some cases, assessment of electricity consumption may not be fully reliable. It is mostly due to certain simplifying assumptions underlying the computation and measurement procedures (for example, too general classifications of lift installations in terms of their functional features, leaving much room for interpretations, adopting hypothetical models of duty cycle of the machine identical for all types of buildings and installations, or a simplified procedure of energy consumption measurements taken during the test ride only and for a short period of time in the standby mode), affecting the final classification results. In order to accurately establish the energy performance of a machine or installation, it is required that several factors impacting on the actual power consumption are taken into account. Operating and energy performance parameters determined under the service conditions are of particular importance. Accordingly, a new method was worked out to determine the energy efficiency ratings of lift installations based on measurements taken with the purpose-built system to support energy performance measurements and energy parameter acquisition.

\section{Estimator of the energy efficient classification-main objectives}

Underlying the energy efficiency classification system are the following assumptions summarised in (Krakowski et al. 2015):

- Recording of operating and energy performance parameters of a lift installation enables reliable assessment of its energy efficiency ratings;

- It is required that energy performance parameters of the lift installation (active power ratings of the drive unit, of the lift car unit and of the entire lift) as well as operating parameters (distance travelled, transported mass, travel time, the number of trips) are registered over a weekly duty cycle in the form of time dependencies;

- Important from drive and energy usage point of view construction factors (e.g. roping type and overbalancing of the system) and operation parameters (e.g. acceleration, deceleration and direction of travel) are included in the results of actual energy consumption measurement;

- The week-long recording time allows duty cycle of the lift to be accurately modelled, the model being specific to the given lift installation operated in the building;

- Time dependencies determined over a weekly duty cycle (e.g. excluding holidays or idle time) of operating and energy performance parameters are determined recalling the usage patterns and can be taken as repeatable in other weeks with the allowed uncertainty limits. Recurring passenger traffic conditions for lifts and escalators have been described by (Tukia et al. 2016a, b; Uimonen et al. 2017);

- The energy efficiency rating of a lift installation is not constant, it varies with the changes in energy uptake during the ride, in the standby mode and in relation to operating parameters, such as for example the transported mass or the distance covered, travel direction, speed, acceleration and deceleration;

- A parameter is introduced expressing the usage factor or operational equipment effectiveness for the lift;

- To determine the energy efficiency rating of a lift installation, it is required that the running and standby energy efficiency and operational equipment effectiveness factor variations are plotted in the function of time;

- Thus, obtained time dependencies of the energy efficiency ratings yield the average energy efficiency which can be treated as the final value in the classification procedure.

These assumptions have underpinned the developed heuristic estimator of the energy efficiency ratings of lift installations. It relies on the fuzzy logic approach, enabling us to solve problems involved in nonlinear relationships between variables characterising the object, an incomplete model of the object and interactions due to non-measurable disturbances. This approach facilitates the data analysis, particularly in the case of multidimensional objects. 
The lift energy efficiency classification requires common criteria for assessing a diversity of objects, whilst the actual energy efficiency ratings involve several factors, rendering the fuzzy logic approach a viable solution. The fuzzy logic estimator was developed using the Matlab-Simulink packages complete with the Fuzzy Logic toolbox. Thus, developed fuzzy model is constructed using the Mamdani-type linguistic approach.

\section{Estimator of lift energy efficiency}

The energy efficiency classification and certification procedure use the time dependencies of operating and energy performance parameters of the analysed lift. A purpose-built data acquisition system is used which registers lift parameters (Krakowski et al. 2013, 2015). The outlined lift efficiency classification procedure relies on distributions of parameters listed in Table 1 determined on an hourly basis. In the light of the underlying assumptions, the distribution patterns should cover a 7-day duty cycle. The calculation procedure uses also lift parameters collated in Table 2.

The maximal possible number of trips within 1-h running under the maximal lift loading $\left(l_{J G}\right)$ can be determined by measurements or derived from Formula (1):

$l_{J G}=\frac{3600}{t_{J \mathrm{MAX}}}$

where $t_{J \max }$ indicates the maximal length of the duty cycle from instant the maximal admissible number of

Table 1 Operating and energy performance parameters required for lift energy efficiency classification

\begin{tabular}{|c|c|c|c|}
\hline No. & Parameter & Unit & Symbol \\
\hline 1 & $\begin{array}{l}\text { Energy consumption per } 1 \mathrm{~h} \text { of lift } \\
\text { operation }\end{array}$ & $(\mathrm{Wh})$ & $E$ \\
\hline 2 & Running energy consumption per $1 \mathrm{~h}$ & $(\mathrm{Wh})$ & $E_{J}$ \\
\hline 3 & $\begin{array}{l}\text { Non-running (idle/standby) energy } \\
\text { consumption per } 1 \mathrm{~h}\end{array}$ & $(\mathrm{Wh})$ & $E_{C}$ \\
\hline 4 & $\begin{array}{l}\text { Energy consumption by the lift drive per } \\
1 \mathrm{~h}\end{array}$ & $(\mathrm{Wh})$ & $E_{N}$ \\
\hline 5 & $\begin{array}{l}\text { Distance travelled by the lift per } 1 \mathrm{~h} \text { of } \\
\text { running }\end{array}$ & $(\mathrm{m})$ & $S$ \\
\hline 6 & Total load carried by the lift in $1 \mathrm{~h}$ & $(\mathrm{~kg})$ & $m$ \\
\hline 7 & Total travel time during 1 -h running & (h) & $t_{J}$ \\
\hline 8 & Number of trips during 1-h running & $(-)$ & $l_{J}$ \\
\hline
\end{tabular}

Table 2 Technical data required for lift energy efficiency classification

\begin{tabular}{|c|c|c|c|}
\hline No. & Parameter & Unit & Symbol \\
\hline 1 & Nominal loading capacity & $(\mathrm{kg})$ & $Q$ \\
\hline 2 & Hoisting height & $(\mathrm{m})$ & $H$ \\
\hline 3 & $\begin{array}{l}\text { Maximal possible number of trips within 1-h } \\
\text { running under the maximal lift loading }\end{array}$ & $(-)$ & $l_{J G}$ \\
\hline
\end{tabular}

passengers enters the lift car to door closing, travel between two final levels, door opening, right through to the moment the maximal admissible number of passengers leaves the car.

The estimator structure is shown schematically in Fig. 1. Measured hourly distributions of performance parameters are summarised in Table 1 and the data compiled in Table 2 enter the data processing block yielding the values of input parameters for further calculations in the fuzzy logic estimator block:

- running energy factor $F_{J}$, derived from the formula:

$F_{J}= \begin{cases}0 & \text { if } l_{J}=0 \\ \frac{E_{J}}{S \cdot\left(\frac{m}{l_{J}}\right)} \cdot 1000 & \text { if } l_{J}>0\end{cases}$

- average active power in the standby mode $P_{C}$, derived from the formula:

$$
P_{C}= \begin{cases}0 & \text { if } t_{J}=1 \\ \frac{E_{C}}{1-t_{J}} & \text { if } t_{J}<1\end{cases}
$$

- energy consumption factor of the drive $i_{E}$, expressed as the ratio of energy consumption by the driving unit $E_{N}$ to total energy consumption by the entire installation per $1 \mathrm{~h} E$, derived from the formula: 
Fig. 1 Fuzzy logic estimator for lift energy efficiency classification (symbol designations given in Tables 1 and 2)

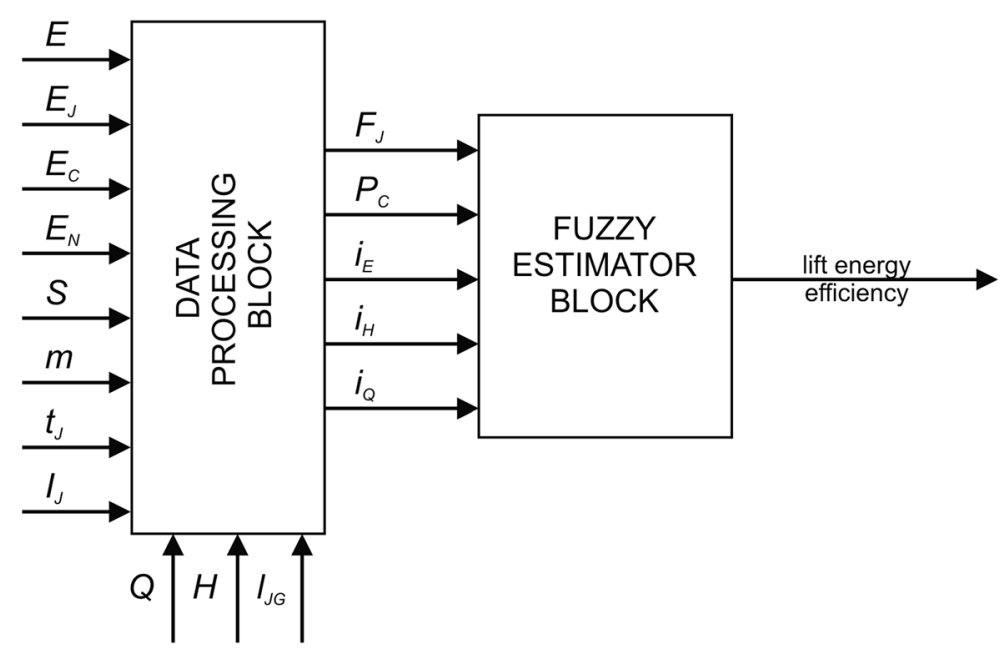

(4)

$i_{Q}=\frac{m}{Q \cdot l_{J G}}$

- travel distance factor $i_{H}$, expressing the ratio of running distance $S$ travelled by the lift per $1 \mathrm{~h}$ to the maximal possible distance travelled by the lift in $1 \mathrm{~h}$ under the maximal loading $\left(H l_{J G}\right)$ :

$i_{H}=\frac{S}{H \cdot l_{J G}}$

The fuzzy estimator block is shown schematically in Fig. 2. It incorporates four sections which determine:

- running lift energy efficiency ratings $k l_{J}$ (FLC_1)

- standby lift energy efficiency ratings $k l_{C}$ (FLC_2)

- operational equipment effectiveness of the lift $w_{c}$, $w_{j}$ (FLC_3)

- lift energy efficiency ratings $k l$ (MOD_1)

- loading factor $i_{Q}$ indicates the ratio of mass carried by the lift $m$ in $1 \mathrm{~h}$ to the maximal possible mass carried by the lift in $1 \mathrm{~h}\left(Q l_{J G}\right)$, derived from the formula:

Incorporating a number of controllers in the estimator allowed for reducing the number of fuzzy rules.
Fig. 2 Lift energy efficiency estimator

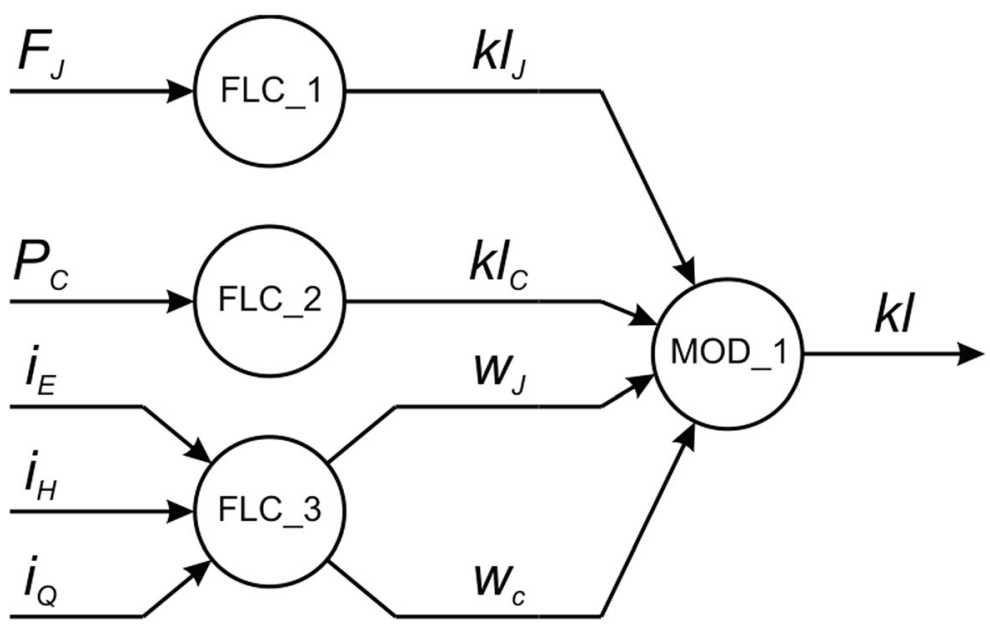




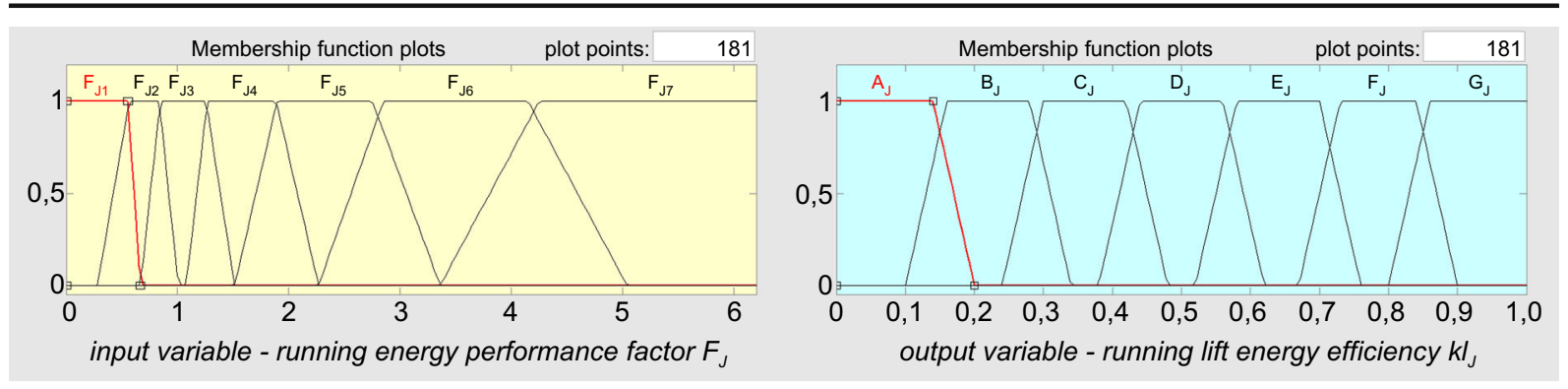

Fig. 3 Membership functions of the input (left-hand side) and output (right-hand side) of the fuzzy estimator of running lift energy efficiency

Results determined in the data processing block in hourly intervals yield the running and standby lift energy efficiency and the lift energy efficiency ratings, expressed by numerical values ranging from 0 to 1 , where 0 represents the best-in-class system and 1 the least favourable result. Numerical values can be assigned letter symbols used in other energy efficiency labelling systems (from A to $G$, where A represents the best-in-class, $G$ represents the least favourable result). The energy efficiency classification can be also defined by a two-term expression, the first term pertaining to the running efficiency rating, the other to the standby energy efficiency ratings (for instance $\mathrm{A} / \mathrm{G}$ ).

Running lift energy efficiency $k l_{J}$ is not constant as it varies with changing performance parameters. In the estimation model considered in this study, it is determined in the block FLC_1 (Fig. 2). The input data to the fuzzy model is the running energy performance factor $F_{J}$ derived from Formula (2), the membership function is shown in Fig. 3. Critical values of intervals are those specified in (VDI 4707-1 2009). The membership function for the model output (running lift energy efficiency $k l_{J}$ ) is shown in Fig. 3. The dependence of the output variable (running lift energy efficiency $k l_{J}$ ) on the input variable $F_{J}$ for the developed fuzzy model is shown in Fig. 4.

The lift standby energy efficiency $k l_{C}$, dependent on energy consumption during the standby and idle time, is determined in the block FLC_2 (Fig. 2). The input

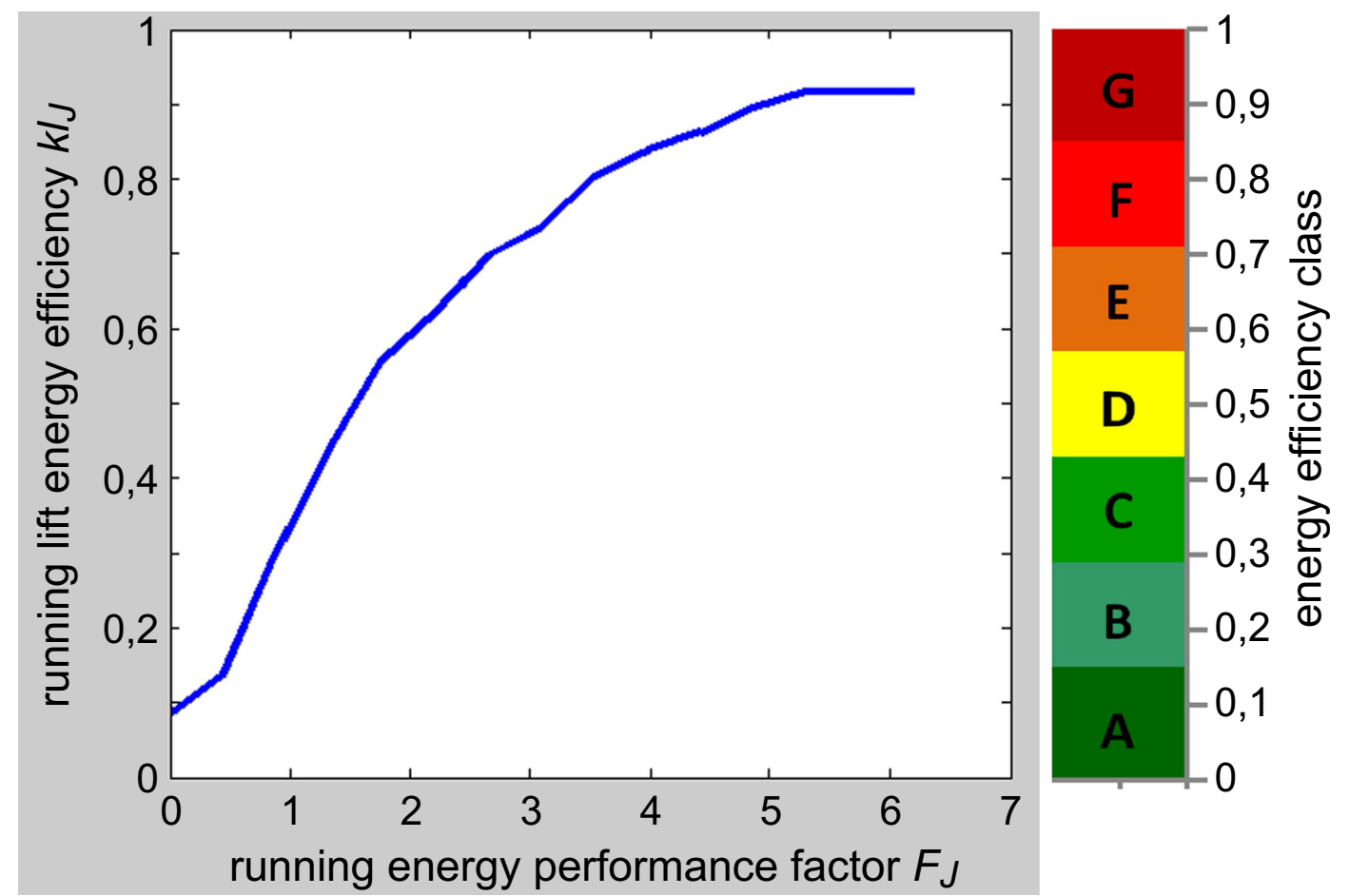

Fig. 4 Output variable (running lift energy efficiency $k l_{J}$ ) vs input variable (running energy performance factor $F_{J}$ ) 

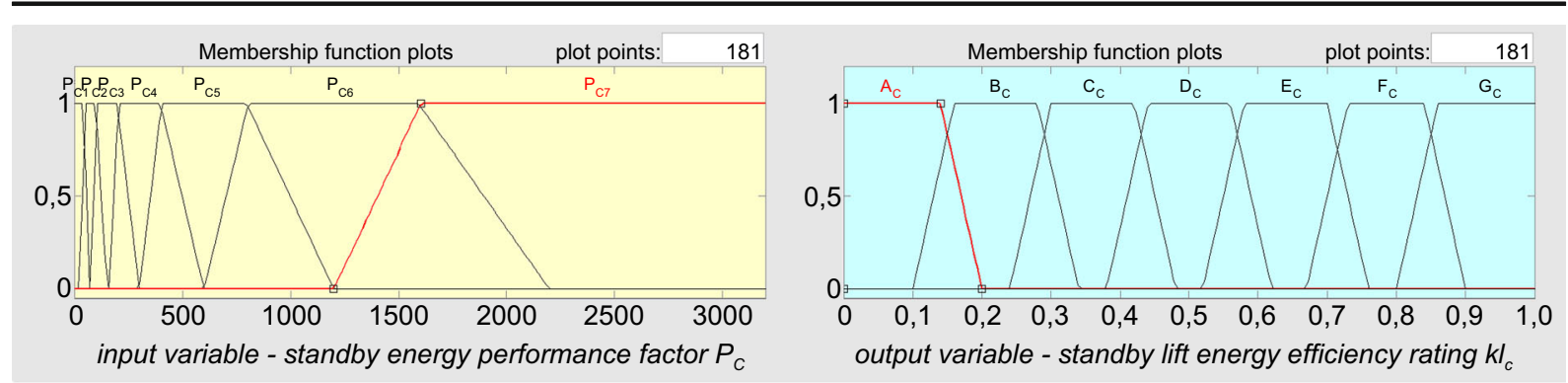

Fig. 5 Membership functions of the input (left-hand side) and output (right-hand side) of the fuzzy estimator of standby lift energy efficiency

parameter in the model is the average standby active power $P_{C}$, derived from Formula (3) and the membership function associated with this variable is shown in Fig. 5. The critical values of intervals are those specified in (VDI 4707-1 2009).

The membership function associated with the output variable and the standby lift energy efficiency rating is illustrated in Fig. 5. This function is the same as in the calculations of running energy efficiency. The dependence of the output variable (standby lift energy efficiency rating $k l_{C}$ ) on the input variable $P_{C}$ for the considered fuzzy model is shown in Fig. 6.

The overall lift energy efficiency rating $k l$ is the resultant per $1 \mathrm{~h}$ of the running energy efficiency rating $k l_{J}$, standby energy efficiency rating $P_{C}$, running operational equipmentefficiency $w_{J}$ and standby equipment efficiency $w_{C}$. Its value varies with performance parameters of the lift and the ratio of non-running to running time. The operational equipment effectiveness factor incorporated in the energy efficiency classification system is dependent on the running time, energy consumption by the drive, energy consumption by the entire lift, load carried and distance travelled within the specified time. The operational equipment effectiveness is determined in the block FLC_3 (Fig. 2). Input parameters in the fuzzy model are as follows:

- $\quad i_{\mathrm{E}}$ is the ratio of energy used by the driving unit to energy expended by the entire lift installation per $1 \mathrm{~h}$ (derived from Formula (4)),

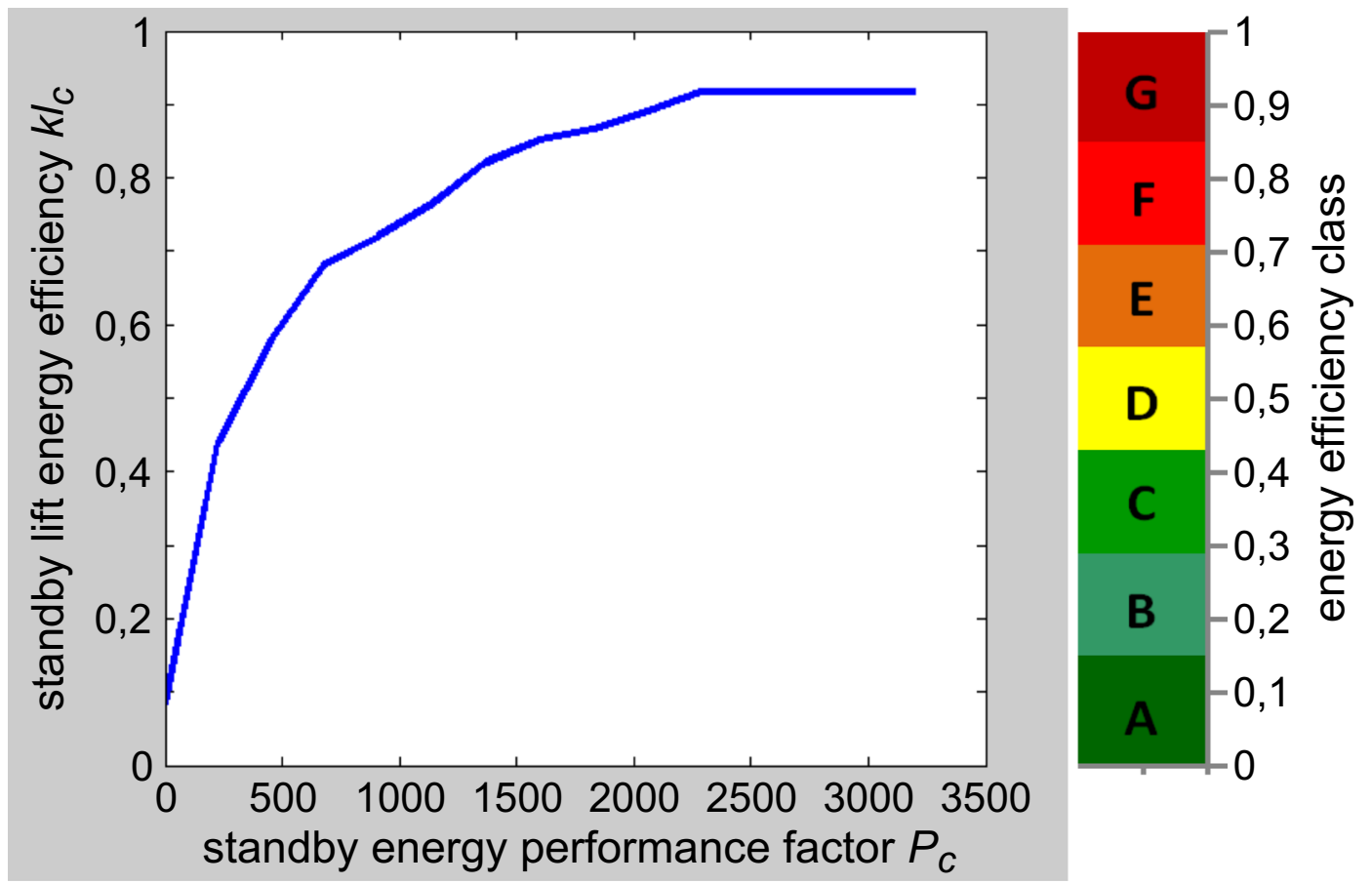

Fig. 6 Output variable (standby lift energy efficiency $k l_{C}$ ) vs input variable (standby energy performance factor $P_{C}$ ) 


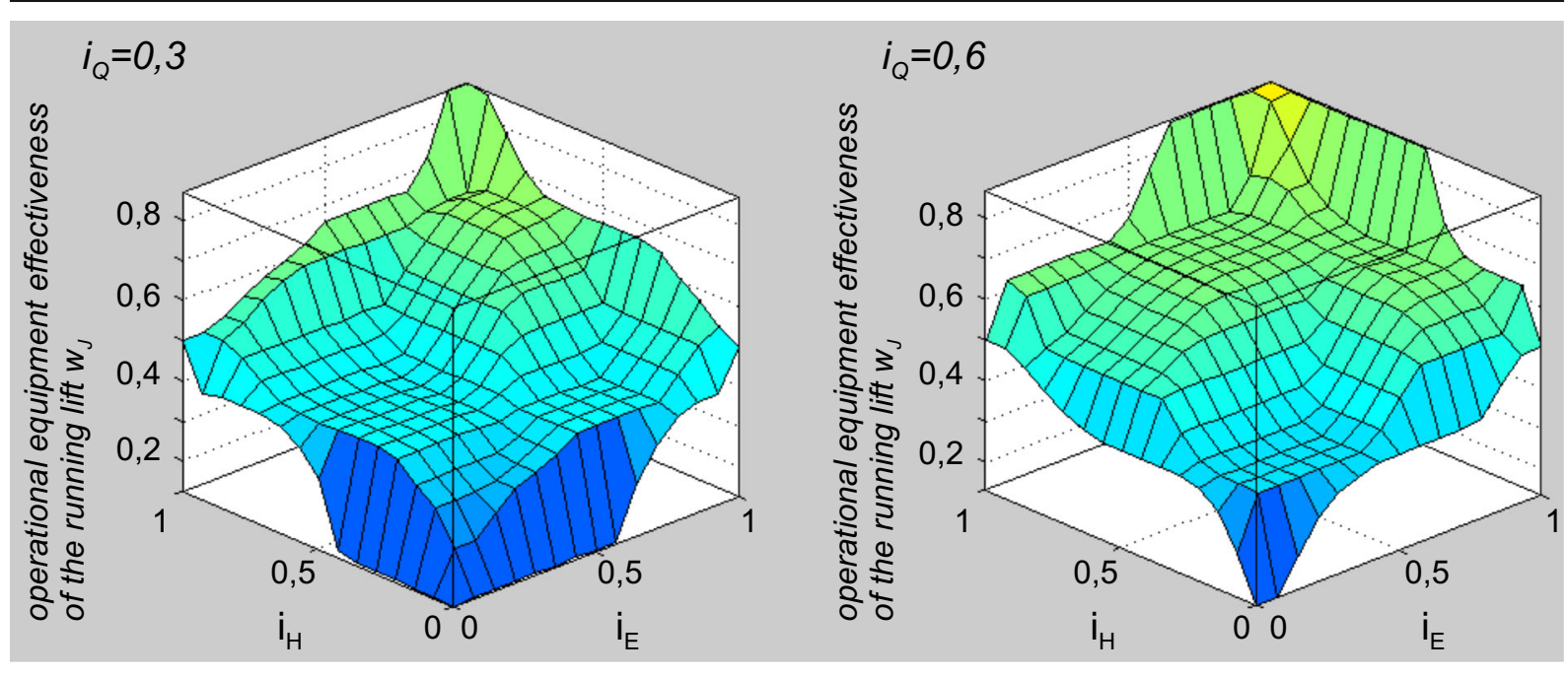

Fig. 7 Output variable (operational equipment effectiveness of the running lift $w_{J}$ ) vs input variables: the running distance factor $i_{H}$ and energy consumption by the drive $i_{E}$ for the constant value of the lifting capacity factor $i_{Q}$

- $i_{\mathrm{H}}$ is the ratio of distance travelled by the running lift per $1 \mathrm{~h}$ to the maximal possible distance travelled by the lift in $1 \mathrm{~h}$ and under the maximal loading (Formula (5)),

- $i_{\mathrm{Q}}$ is the ratio of load mass $(\mathrm{m})$ carried by the running lift per $1 \mathrm{~h}$ to the maximal possible mass that can be carried in $1 \mathrm{~h}$, derived from Formula (6).

Two output parameters are as follows:

- operational equipment effectiveness of the running lift $\left(w_{J}\right)$, which becomes 0 when the lift is idle and 1 when the operational effectiveness of the running lift is maximal in terms of distance travelled, carried load and the operating mode,

- operational equipment effectiveness in the standby mode $\left(w_{C}\right)$, which becomes 0 when no standby occurs (the lift is running all the time) and 1 during standby mode operation occurs (no running).

In the model outlined in this study, the set of rules is complementary (i.e. all possibilities are accounted for), comprising 125 rules constructed by the heuristic method utilising the trial and error approach and the expert's knowledge.

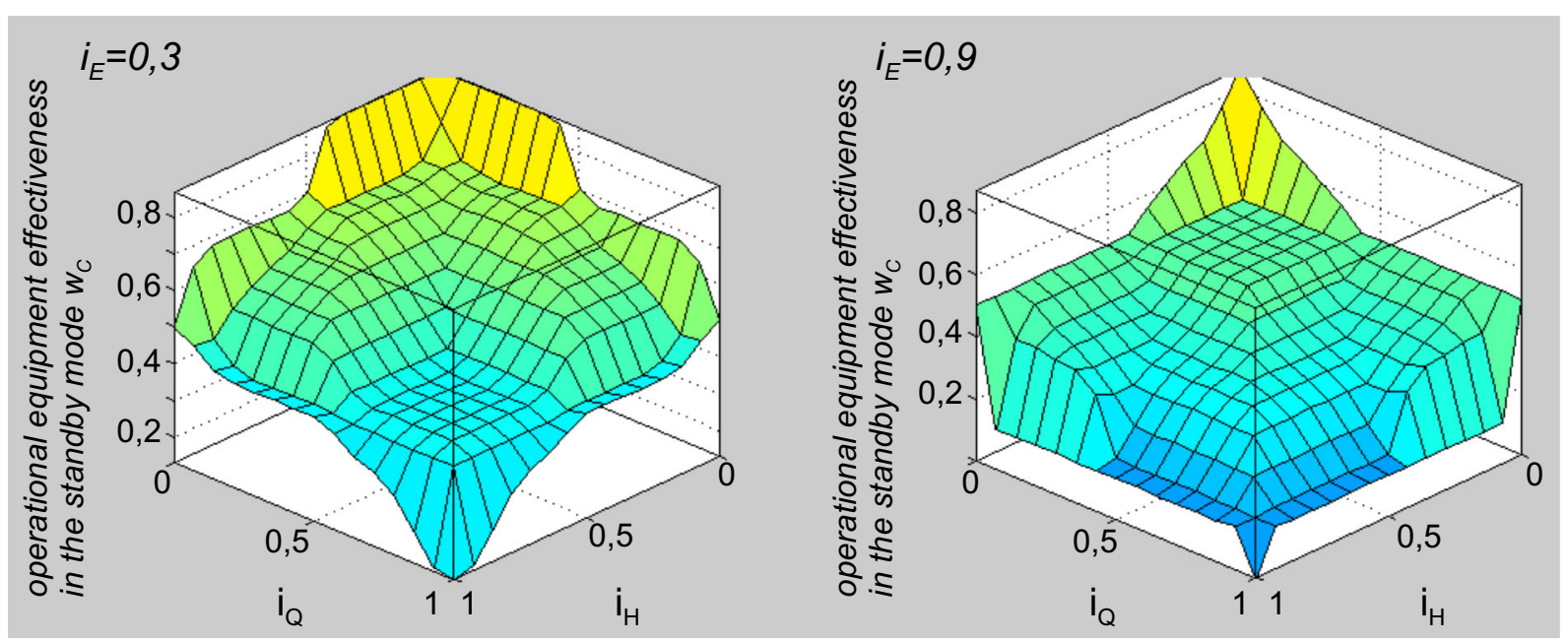

Fig. 8 Output variable (operational equipment effectiveness in the standby mode $w_{C}$ ) vs input variables: the running distance factor $i_{Q}$ and loading factor $i_{H}$, for the constant value of the lifting capacity factor $i_{E}$ 
In the fuzzy model providing the procedure to find operational equipment effectiveness of the lift, the dependence of output variables $\left(w_{J}\right.$ and $\left.w_{C}\right)$ on input variables is shown in Figs. 7 and 8 and the obtained control surfaces confirm the adequacy of the membership functions and fuzzy rules.

In further step of the calculation procedure, the operational equipment effectiveness factors are expressed in the block MOD_1 (Fig. 2) as weights needed to find the weighted average of the running lift energy efficiency $k l_{J}$ determined in the block FLC_ 1 and the standby lift energy efficiency $k l_{C}$ determined in the block FLC_2.

$k l=\frac{k l_{C} \cdot w_{C}+k l_{J} \cdot w_{J}}{w_{C}+w_{J}}$

The result, expressed as the lift energy efficiency rating $k l$, is used in the final energy efficiency classification and certification procedure classifying lift installations according to their energy performance.

As stated in the objectives of the energy efficiency classification system, the energy efficiency rating of an installation varies with the lift performance parameters. That is why the final result is given as variations of $k l$ within hourly time intervals throughout the weekly period in which energy performance of the lift and operating parameters are registered. The average value $k l_{S}$ is obtained, representing the medium energy efficiency rating.

\section{Verification of the energy efficiency estimator}

The verification procedure was conducted on the lift installations in one of the buildings of the AGH-UST. Operating and energy performance parameters of the lift were registered using a portable data acquisition system (Krakowski et al. 2015). The data acquisition system PIP-J6 was connected to the signal conditioning unit connected to the lift drive and control system. The diversity of control systems available in passenger lifts and the number of parameters to be registered necessitated the design and engineering of two data acquisition systems for each lift installation. The first system was installed in the machinery room (Fig. 9) and connected to the drive and control systems and to the lift drive; the other unit was positioned on top of the lift car (Fig. 10) to enable the recording of energy performance parameters of car subassemblies as well as operating

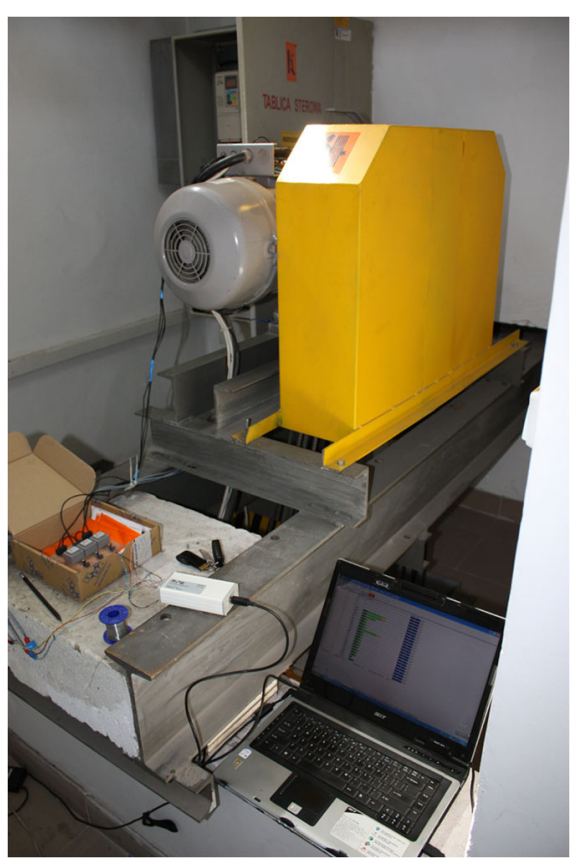

Fig. 9 Data acquisition system in the machinery room

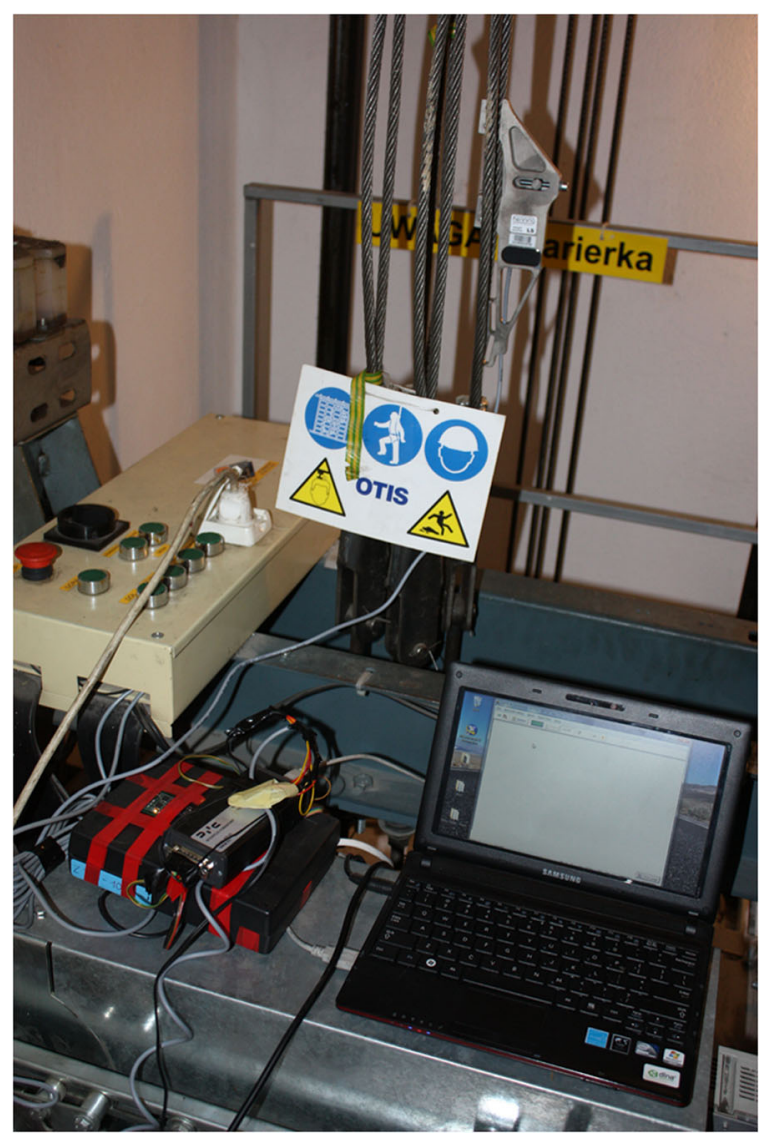

Fig. 10 Data acquisition system on top of the lift car 


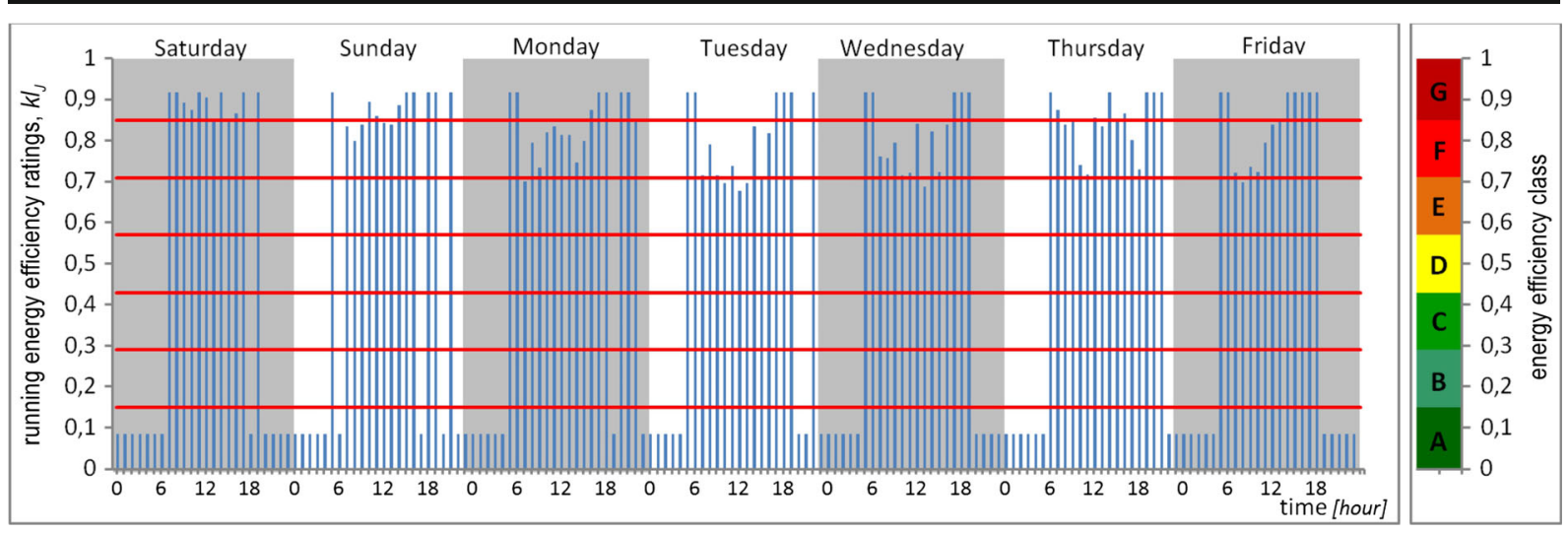

Fig. 11 Running mode lift energy efficiency ratings $k l_{J}$ per $1 \mathrm{~h}$ in a 7-day duty cycle

parameters, such as lift car loading. Measurement data yield the characteristics required for energy efficiency classification procedure: energy performance and operational parameters are summarised in Table 1.

The data registered in accordance with the outlined energy efficiency classification procedure yield the energy efficiency ratings of the lift installation. Accordingly, the values were determined representing the energy efficiency variations during a 7-day duty cycle. Figure 11 shows the variations of the running energy efficiency ratings of the lift $\left(k l_{J}\right)$, and variations of the standby lift energy efficiency $\left(k l_{C}\right)$ are illustrated in

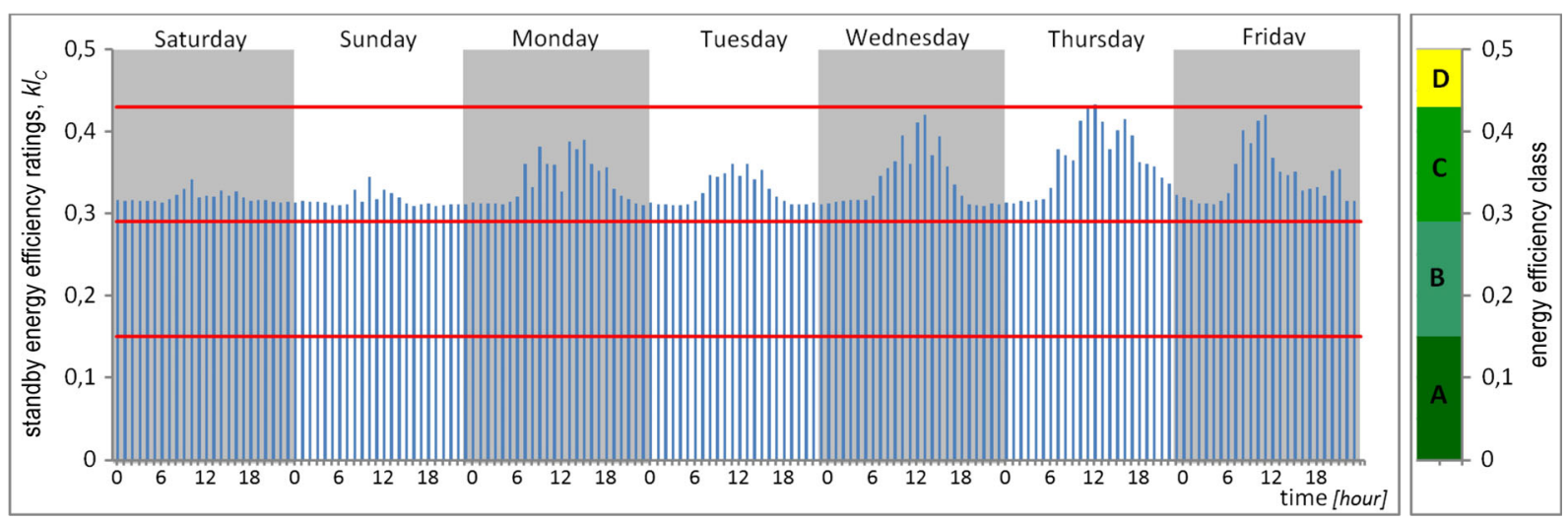

Fig. 12 Standby mode energy efficiency ratings $k l_{C}$ per $1 \mathrm{~h}$ in a 7-day duty cycle

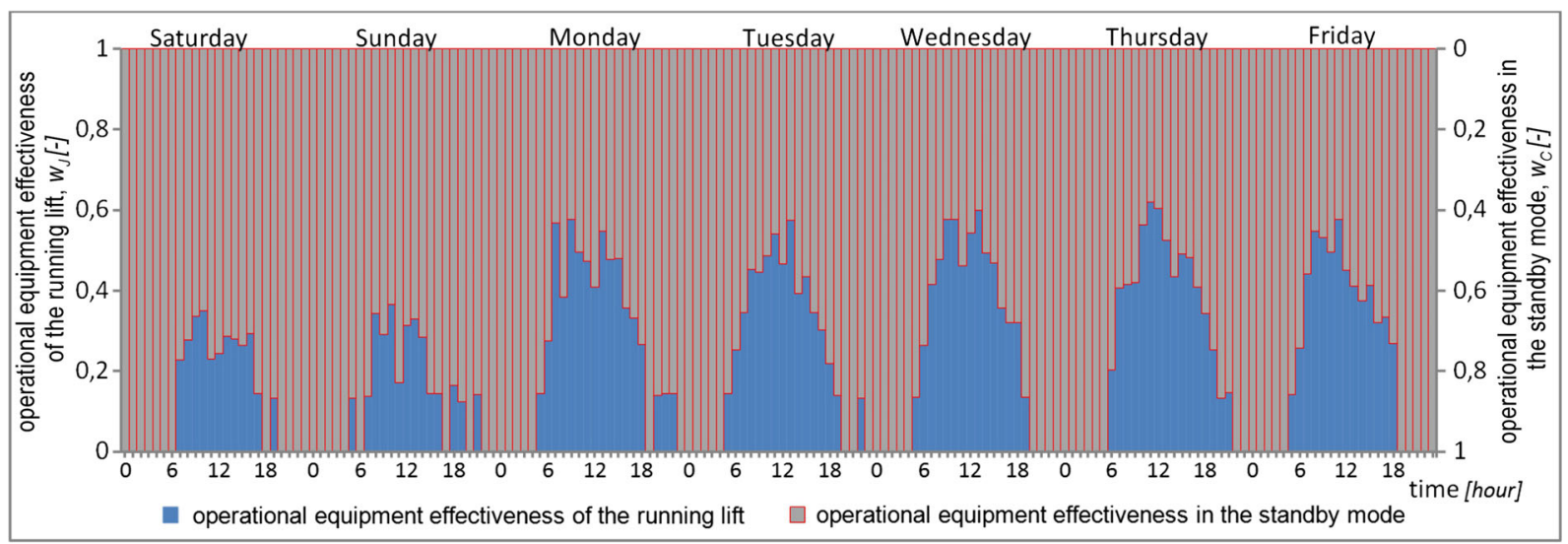

Fig. 13 Operational equipment effectiveness of the running lift $w_{J}$ and in the standby $w_{C}$ per $1 \mathrm{~h}$ in a 7 -day duty cycle 


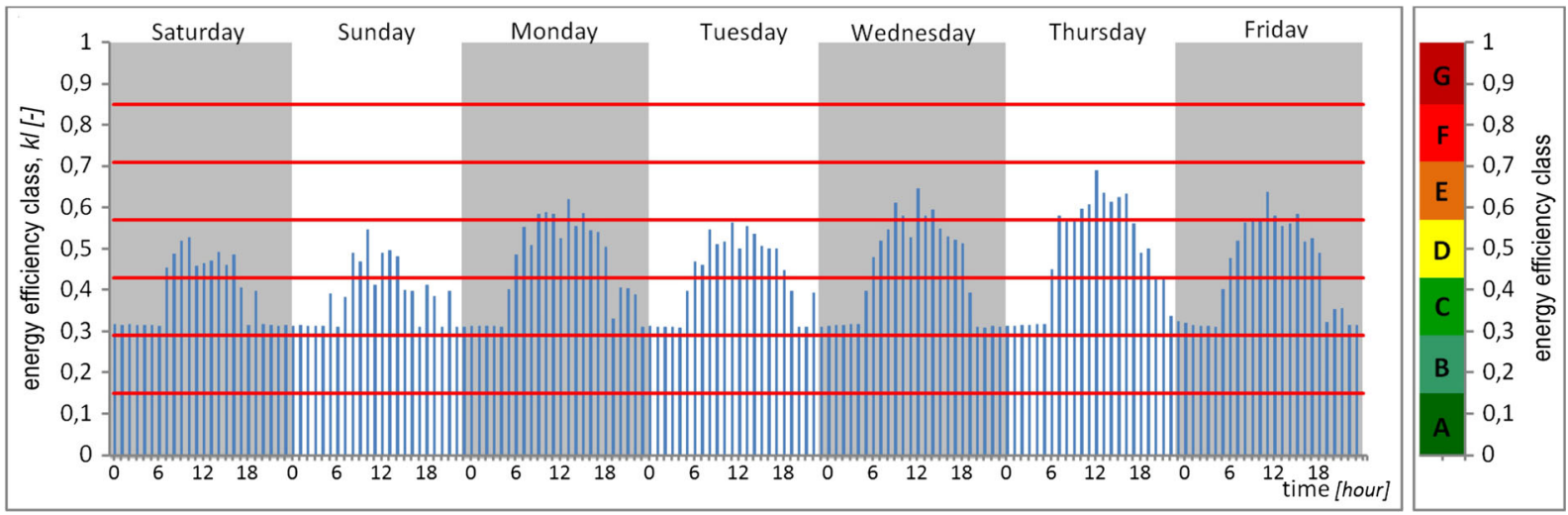

Fig. 14 Lift energy efficiency ratings $k l$ per $1 \mathrm{~h}$ in a 7-day duty cycle

Fig. 12. Figure 13 shows the operational equipment effectiveness of the running lift $\left(w_{J}\right.$ and in the standby mode $w_{C}$ ). Figure 14 shows the final result of the classification procedure expressed as the lift energy efficiency class $(k l)$. It is derived as the weighted average of the running and standby energy efficiency, the weight being taken as the operational equipment effectiveness.

The adopted energy efficiency classification system allowed for finding the medium energy efficiency ratings of a lift on each separate day (Table 3) and for the entire week (Table 4). Basing on the relevant ranges expressing the energy efficiency ratings and corresponding symbols, energy efficiency classes are labelled with letter symbols. Following the analysis of a weekly duty cycle and energy performance and operating parameters registered within that period, the energy efficiency of the

Table 3 Energy efficiency classification ratings obtained by the outlined method

\begin{tabular}{|c|c|c|c|c|c|c|}
\hline \multirow[t]{2}{*}{ Day of the week } & \multicolumn{2}{|c|}{$\begin{array}{l}\text { Average } \\
\text { running } \\
\text { energy } \\
\text { efficiency } \\
\text { rating }\end{array}$} & \multicolumn{2}{|c|}{$\begin{array}{l}\text { Average } \\
\text { standby } \\
\text { energy } \\
\text { efficiency } \\
\text { rating }\end{array}$} & \multicolumn{2}{|c|}{$\begin{array}{l}\text { Average } \\
\text { energy } \\
\text { efficiency } \\
\text { rating }\end{array}$} \\
\hline & $k l_{J S}$ & & $k l_{C S}$ & & $k l_{S}$ & \\
\hline Saturday & 0.49 & $\mathrm{D}$ & 0.32 & $\mathrm{C}$ & 0.39 & $\mathrm{C}$ \\
\hline Sunday & 0.55 & $\mathrm{D}$ & 0.32 & $\mathrm{C}$ & 0.39 & $\mathrm{C}$ \\
\hline Monday & 0.62 & $\mathrm{E}$ & 0.34 & $\mathrm{C}$ & 0.46 & $\mathrm{D}$ \\
\hline Tuesday & 0.56 & $\mathrm{D}$ & 0.33 & $\mathrm{C}$ & 0.43 & $\mathrm{C}$ \\
\hline Wednesday & 0.54 & $\mathrm{D}$ & 0.34 & $\mathrm{C}$ & 0.45 & $\mathrm{D}$ \\
\hline Thursday & 0.59 & $\mathrm{E}$ & 0.36 & $\mathrm{C}$ & 0.48 & $\mathrm{D}$ \\
\hline Friday & 0.53 & $\mathrm{D}$ & 0.34 & $\mathrm{C}$ & 0.45 & $\mathrm{D}$ \\
\hline Weekly duty cycle & 0.55 & $\mathrm{D}$ & 0.34 & $\mathrm{C}$ & 0.43 & D \\
\hline
\end{tabular}

investigated lift was rated as class D. The running energy efficiency was rated as class $\mathrm{D}$, the standby efficiency as class $\mathrm{C}$.

The results were obtained for 1 week of service of the lift. Measurements were taken for 10 weeks, allowing the uncertainty levels to be determined (Table 4) and demonstrating that a weekly duty cycle well captures the repeatability patterns of the lift usage; hence, the results can be considered reliable.

\section{Energy consumption comparison and discussion}

Two main energy efficiency classification methods that are currently used: VDI 4707-1 guideline ISO 25745-2 standard, based on the energy consumption estimated on measurements (running energy consumption of reference cycle and short cycle, standby power) and assumed or measured values and factors dependent on building type describing model and usage intensity, (e.g. number of trips, running time, standby time, average travel distance, average car load, load factor, time ratios of standby mode). Such approach in case of some devices may lead to inadequate and not reliable energy consumption value (Tukia et al. 2016a; Krakowski and Ruta 2018) which in consequence leads to inaccurate energy efficiency classification. More accurate methods of establishing energy consumption of elevators are proposed by other authors, for example Tukia et al. 2016a rely on measuring the energy consumption of most prevailing day types and linearly extrapolating the annual consumption.

Total, running and standby daily average measured and calculated energy consumption for the analysed device according to VDI 4707 and ISO 25745-2 are 
Table 4 Energy efficiency classification within a weekly duty cycle

\begin{tabular}{|c|c|c|c|c|c|}
\hline \multirow[t]{2}{*}{ Designation } & \multirow[t]{2}{*}{ Symbol } & \multicolumn{2}{|c|}{ Average value } & \multirow{2}{*}{$\begin{array}{l}\text { Standard deviation } \\
\text { obtained experimentally } \\
\text { Relative standard deviation } \\
\text { obtained experimentally } \\
s\left(q_{k}\right)\end{array}$} & \multirow{2}{*}{$\begin{array}{l}\text { Standard deviation of the mean } \\
\text { value obtained experimentally } \\
\text { Relative standard deviation of } \\
\text { the mean value obtained } \\
\text { experimentally } \\
s(\bar{q})\end{array}$} \\
\hline & & $\bar{q}$ & & & \\
\hline Running energy efficiency ratings & $k l_{J S}$ & 0.53 & $\mathrm{D}$ & $\begin{array}{l}0.028(-) \\
5.33(\%)\end{array}$ & $\begin{array}{l}0.009(-) \\
1.69(\%)\end{array}$ \\
\hline Standby energy efficiency ratings & $k l_{C S}$ & 0.34 & $\mathrm{C}$ & $\begin{array}{l}0.011(-) \\
3.25(\%)\end{array}$ & $\begin{array}{l}0.0035(-) \\
1.03(\%)\end{array}$ \\
\hline Overall lift energy efficiency ratings & $k l_{S}$ & 0.44 & $\mathrm{D}$ & $\begin{array}{l}0.0258(-) \\
5.89(\%)\end{array}$ & $\begin{array}{l}0.0082(-) \\
1.86(\%)\end{array}$ \\
\hline
\end{tabular}

shown in Fig. 15. These values have been counted based on construction data specific for the device (Table 5), measurements performed according to ISO 25745-1 (Table 6) as well as values and factors specified in the guidelines and counted based on measured operation parameters (Table 7).

In the analysed device, even assuming actual parameters describing lift operation leads to inaccurate energy consumption value. Energy consumption in standby mode is similar to the measurements. Significant difference occurs however in energy consumed in running mode, which is $28 \%$ of measured value in case of calculations according to VDI, $63 \%$ in case of VDI monitored, $59 \%$ for ISO and $40 \%$ according to ISO monitored.
Using VDI and ISO in some instances may cause that the results of energy consumption calculations may be inaccurate. Even assumption of measured operating parameters in calculations may not lead to establishing accurate value of energy consumption, which is crucial in energy efficiency classification process. Devices which operation is similar to model assumed in guidelines will have reduced uncertainty of calculations and their classification will be defined properly. On the other hand, devices deviating with their operating specifics from this proposed in the model will be classified as better or worse than in reality.

Defined energy efficiency class of the device is not constant and depends on construction and

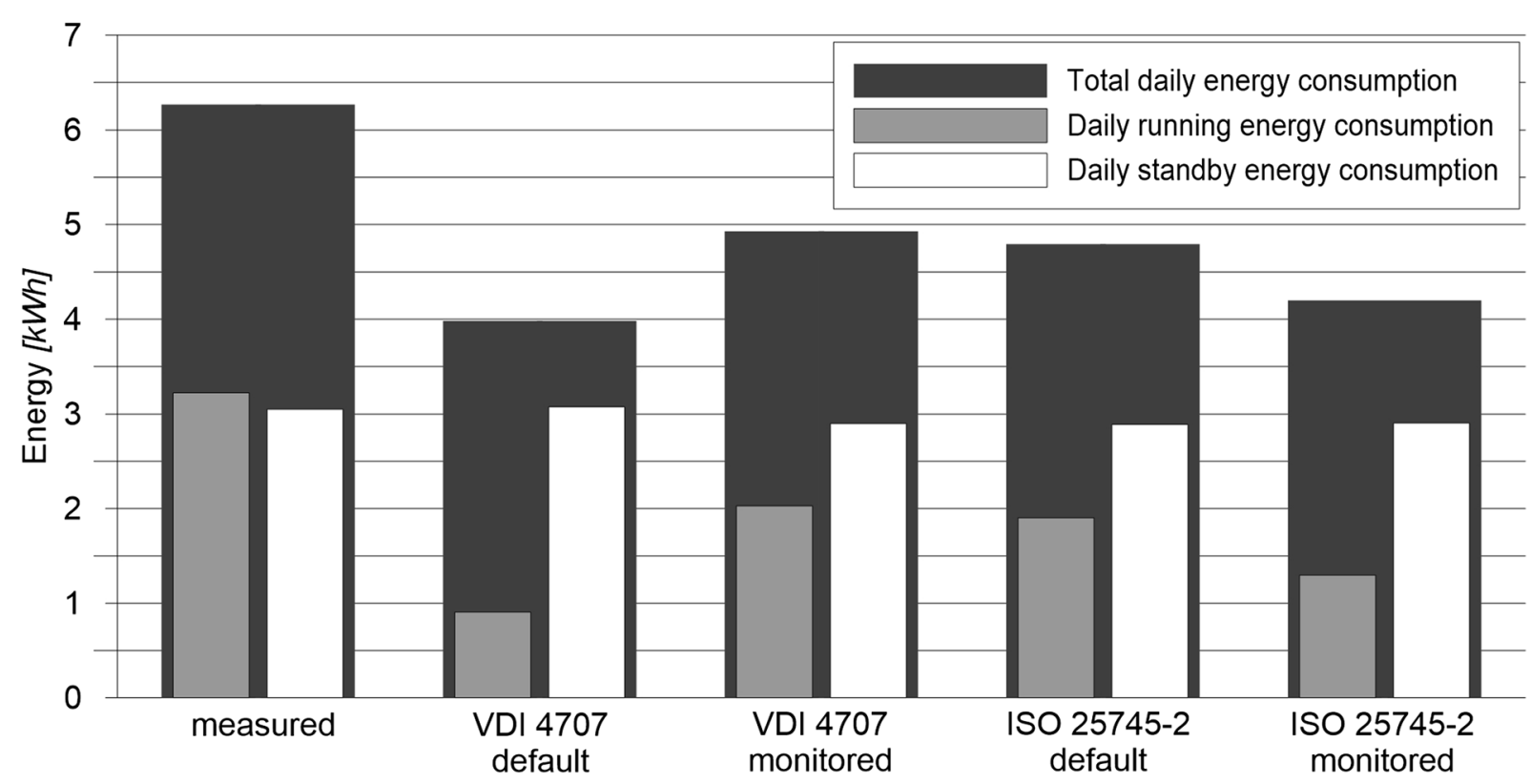

Fig. 15 Total, running and standby daily average measured and calculated (according to VDI 4707 and ISO 25745-2) energy consumption 
Table 5 Technical specification of monitored lift

\begin{tabular}{ll}
\hline Rated load & $400(\mathrm{~kg})$ \\
Travel & $17.33(\mathrm{~m})$ \\
Rated speed & $1(\mathrm{~m} / \mathrm{s})$ \\
Counterbalancing & $50 \%$ \\
Suspension & $1: 1$ \\
\hline
\end{tabular}

operating parameters. Apart from knowing the accurate value of energy consumption, to determine the class, the travel distance and load to which this energy was used need to be identified. In the VDI and ISO methods, these values are hypothetical and identical for particular group of devices. Thus, it is possible that commonly used operation model dedicated for particular location will be inaccurate for some devices.

Proposed approach as opposed to VDI and ISO methods, which are estimators of energy consumption and energy efficiency classification, is a method basing on measures performed in a weekly operating cycle. Due to multi-dimensionality of analysed objects of incomplete model, large number of variables impacting the final result and significant diversity of objects analysed, it has been decided to use fuzzy logic tool basing on the results of measures performed on a real object. This approach enabled easier analysis of multidimensional data, adopting common criteria and obtaining comparable precision of final results.

Using measured values of energy and operating parameters is resulting in receiving actual exploitation model of lift. It is possible to determine the efficiency of lift during its operation together with the parameters changing during the operation. Usage factor of the lift which was introduced can be determined in any time interval and that is why it

Table 6 Data determined by measurements (according to ISO 25745-1)

\begin{tabular}{lr}
\hline Reference cycle energy & $24.92(\mathrm{Wh})$ \\
Short cycle energy & $12.93(\mathrm{Wh})$ \\
Idle power & $134.9(\mathrm{~W})$ \\
Standby 5 power & $130.9(\mathrm{~W})$ \\
Standby 30 power & $127.1(\mathrm{~W})$ \\
Short cycle distance & $7.2(\mathrm{~m})$ \\
Door operations time & $11(\mathrm{~s})$ \\
\hline
\end{tabular}

takes into account the changing operating conditions of its work. This enables determination of the efficiency of the lift in a particular time interval, e.g. hour, period of intensive or low exploitation. The adopted model is characteristic only for the device under consideration. As a consequence, this approach enables a reliable and accurate completion of the certification process in a repeatable manner and with similar uncertainty.

\section{Conclusions}

When evaluating lifts and escalators, their energy performance and operating parameters measured on a real object are of particular importance. The developed method of lift energy efficiency classification relies on energy performance and operating parameters of lift installations registered over a weekly duty cycle, with the use of purpose-built measurement system. Pertinent parameters registered over a 7-day cycle provide reliable data for energy efficiency assessment, enable the operating parameters to be adjusted to the specificity of the lift location, allowing an objective comparative overview of lift installations. In the proposed approach, the energy efficiency class varies with its operational equipment effectiveness of the lift installation. The estimator of the energy efficiency classification is constructed using the fuzzy logic approach.

Table 7 Average daily traffic parameters

\begin{tabular}{|c|c|c|c|}
\hline & Monitored & $\begin{array}{l}\text { VDI } \\
4707 \\
\text { default }\end{array}$ & $\begin{array}{l}\text { ISO } \\
25745-2 \\
\text { default }\end{array}$ \\
\hline $\begin{array}{l}\text { Average number of trips per } \\
\text { day }\end{array}$ & 357 & - & 300 \\
\hline Average running time per day & $1.85(\mathrm{~h})$ & $0.5(\mathrm{~h})$ & $1.95(\mathrm{~h})$ \\
\hline Average standby time per day & $22.5(\mathrm{~h})$ & $23.5(\mathrm{~h})$ & $22.05(\mathrm{~h})$ \\
\hline $\begin{array}{l}\text { Average daily distance } \\
\text { travelled }\end{array}$ & $4029(\mathrm{~m})$ & $\begin{array}{r}1800 \\
(\mathrm{~m})\end{array}$ & - \\
\hline $\begin{array}{l}\text { Average car load-percentage } \\
\text { of rated load }\end{array}$ & $36 \%$ & - & $7.5 \%$ \\
\hline $\begin{array}{l}\text { Average travel } \\
\text { distance-percentage of } \\
\text { one-way travel distance of } \\
\text { reference cycle according to } \\
\text { ISO 25745-1 }\end{array}$ & $65 \%$ & - & $49 \%$ \\
\hline
\end{tabular}




\section{Compliance with ethical standards}

Conflict of interest The authors declare that they have no conflict of interest.

Open Access This article is distributed under the terms of the Creative Commons Attribution 4.0 International License (http:// creativecommons.org/licenses/by/4.0/), which permits unrestricted use, distribution, and reproduction in any medium, provided you give appropriate credit to the original author(s) and the source, provide a link to the Creative Commons license, and indicate if changes were made.

\section{References}

Almeida, A., Hirzel, S., Patrão, C., Fong, J., \& Dütschke, E. (2012). Energy-efficient elevators and escalators in Europe: an analysis of energy efficiency potentials and policy measures. Energy and Buildings, 47, 151-158.

Al-Sharif, L. (2004). Lift energy consumption: general overview (1974-2001). Elevator World, 52(10), 61-67.

Anand, R., \& Mahesh, M. (2016). Analysis of elevator drives energy consumptions with permanent magnet machines. IEEE Smart Energy Grid Engineering (SEGE), 2016, 186-190.

Anand, R., \& Mahesh, M. (2017). Vertical transportation: an overview on system integration with advance. International Conference On Smart Technologies For Smart Nation (SmartTechCon), 2017, 476-479.

Barney, G. (2013, 2013). Method to calculate the energy consumption of lifts. Elevatori, 36-41.

Doolaard, D. A. (1992). Energy consumption of different types of lift drive system. Elevator Technology, 4, 77-85.

E4 Project, (2010). Energy Efficient Elevators and Escalators (Technical Report).https://ec.europa.eu/energy/intelligent/ projects/sites/iee-projects/files/projects/documents/e4 publishable report en.pdf. Accessed 2 Dec 2017.

Goergiev, I., Mirchevski, S. (2012). Analysis of electrical energy consumption in elevator drives. 15th International Power Electronics and Motion Control Conference, 2012, 1-6.

Goldstein, D. B., \& Eley, C. (2014). A classification of building energy performance indices. Energy Efficiency, 7, 353-375.

ISO 25745-2 (2015) Energy performance of lifts, escalators and moving walks - part 2: energy calculation and classification for lifts (elevators).

Karlis, A. D. (2014). Energy consumption estimation on lift systems: the advantages of VVVF drives. Proc. IEEE ICEM, 751-755.

Krakowski, T., \& Ruta, H. (2018). Analysis and assessment of energy efficiency of passenger lifts. Advances in Science and Technology Research Journal, 12(3), 257-265.

Krakowski, T., Kwaśniewski, J., Grzybowski, J., \& Kordos, D. (2013). Measuring system for testing of passenger lifts. Electrical Review, 9, 113-117.

Krakowski, T., Magiera, T., Molski, S. Z., Ruta, H., \& Kułaga, P. (2015). System for measuring operational and energy parameters of lift installations used to determine their energy efficiency. Logistyka, 4, 9256-9262.

Longwic, R., \& Szydło, K. (2017). The impact of the elevator guides contamination on the braking process delay for selected progressive gears. Advances in Science and Technology Research Journal, 11(2), 1-7.

Lonkwic, P., \& Szydło, K. (2016). Reduction of the cabin acoustic emission by the selection of an optimum stiffening method for the cabin panels. Journal of Measurements in Engineering, 4(2), 95-102.

Lorente, A. M., Gomez, A., Diaz, D., \& Arteche, F. (2010). State of the art calculation methods for elevator energy consumption. Elevator Technology, 18, 225-238.

Nipkow, J. Schalcher, M. (2005). Energy consumption and efficiency potentials of lifts.http://www.arena-energie.ch/d/ data/EEDAL-ID131_Lifts_Nipkow.pdf. Accessed $\overline{5}$ Dec 2017

Papanikolaou, N., Loupis, M., Spiropoulos, N., Mitronikas, E., Tatakis, E., Christodoulou, C., Zarikas, V., \& Tsiftsis, T. (2017). On the investigation of energy saving aspects of commercial lifts. Energy Efficiency, 10, 945-956.

Schroeder, J. (1980). The energy consumption of elevators a comparative analysis. Elevator Technology, 11, 28-31.

Schroeder, J. (1988). Second century of the skyscraper council on tall buildings and urban habitat, energy consumption and power requirements of elevators (pp. 621-627). Boston: Springer.

Siikonen, M-L., Sorsa, J., Hakala, H. (2010). Impact of traffic on annual elevator energy consumption. Elevacon 2010. Elevator technology, 18, 344-353.

Syta, A., \& Lonkwic, P. (2016). Nonlinear analysis of braking delay dynamics for the progressive gears in variable operating conditions. Journal of Vibroengineering., 18(7), 4401-4408.

Szydło, K., Maciag, P., Longwic, R., \& Lotko, M. (2016). Analysis of vibroacoustic signals recorded in the passenger lift cabin. Advances in Science and Technology Research Journal, 10(30), 193-201.

Tukia, T., Uimonen, S., Siikonen, M.-L., Hakala, H., Donghi, C., \& Lehtonen, M. (2016a). Explicit method to predict annual elevator energy consumption in recurring passenger traffic conditions. Journal of Building Engineering, 8, 179-188.

Tukia, T., Uimonen, S., Siikonen, M-L., Donghi, C., Lehtonen, M., (2016b). Evaluating and improving the energy efficiency of counterbalanced elevators based on passenger traffic. 2016 IEEE 16th International Conference on Environment and Electrical Engineering (EEEIC), 2016, 1-6.

Uimonen, S., Tukia, T., Siikonen, M.-L., \& Lehtonen, M. (2017). Predicting the annual escalator energy consumption based on short-term measurements. Journal of Building Engineering, $13,319-325$.

VDI 4707-1 (2009) Guidelines for lifts energy efficiency.

Zhou, N., Mcneil, M., \& Levine, M. (2012). Assessment of building energy-saving policies and programs in China during the 11th five-year plan. Energy Efficiency, 5, 51-64.

Publisher's note Springer Nature remains neutral with regard to jurisdictional claims in published maps and institutional affiliations. 